\title{
Deformation of Mild Steel Plate with Linear Cracks due to Horizontal Compression
}

\author{
Mitsuru Yoshida \\ Fortran Plan Office, 6-24-7 Yutaka-chou, Kasukabe-shi, Saitama-ken 344-0066, Japan
}

\begin{abstract}
Deformation of mild steel plate with linear cracks due to horizontal compression is investigated by the use of 2-D FEM (two-dimensional finite element method) in the case of plane strain. The compound plate has a notch at the upper surface, which links to oblique downward initial defects. The compound plate roughly models the oceanic plate (Plate 1) sinking under the continental plate (Plate 2) near the trough or trench in Japan. A horizontal compression is exerted at the left side of Plate 1. The deformation of the compound plate shows that the notch and upper surface of Plate 2 subside if a downward tension is added to the right side of Plate 1.
\end{abstract}

Key words: Deformation, mild steel plate, finite element method.

\section{Introduction}

Strain and shear stress of compound mild steel plates with linear cracks due to a horizontal compressive force have been investigated by the use of 2-D FEM (two-dimensional finite element method) [1-3]. The compound plate is composed of several materials of different Young's modulus and Poisson's ratio, and the linear cracks PB (Plate Boundary) located at the surface of one plate (Plate 1) are extended from a notch downwards along a line, another plate (Plate 2) being located above Plate 1. The right side of Plate 2 is fixed. Plate 1 is placed on a rigid material LMS (Lower Mild Steel). The compound plate is assumed to be perfectly elastic body. In the present study the deformation of the compound plate is investigated in the case of plane strain, paying attention especially to the deformation of the notch and the upper surface of Plate 2 above the linear cracks.

\section{Structure and Deformation of Pate Model}

The plate models examined are classified into two

\footnotetext{
Corresponding author: Mitsuru Yoshida, Dr.Sci., representative, research field: seismology. E-mail: ymit@mub.biglobe.ne.jp.
}

types from a viewpoint of loading conditions. The first type is the plate model which has no downward tension on Plate 1 (C-Plate; H-Plate; PH-Plate; UMB-Plate; UMB-PB). The second type is the plate model which has downward tension on Plate 1 (UMB-X2; UMB-X5; UMB-X8; UMB-PB-X; UMB-PB-X2). The plate models of the second type are mostly composed of material of the crust of the Philippine Sea plate [4, 5], in which a transition zone UMB (Upper Mantle Boundary) is placed between Plate 1 and LMS. The material of rubber-like-elasticity [6] is assumed for PB and UMB. In detail, the first type is grouped into two models. One is the plate models without UMB (Fig. 1), and another is the one with UMB (Fig. 2). The second type is also grouped into two models. One is the plate models with irregular PB (Fig. 3), and another is the ones with regular PB (Fig. 4). The plate models C-Plate and H-Plate are purely composed of material of mild steel plate [1,2]. Young's modulus of LMS for H-Plate is $0.3 \%$ smaller than that of Plate 1 and Plate 2 (Table 1). The material composition of PH-Plate is identical with that of UMB-Plate and UMB-PB except UMB (Table 1), in which the Young's moduli of Plate 1, Plate 2, and LMS are calculated from the formula $E=2(1+p) G$, using the 


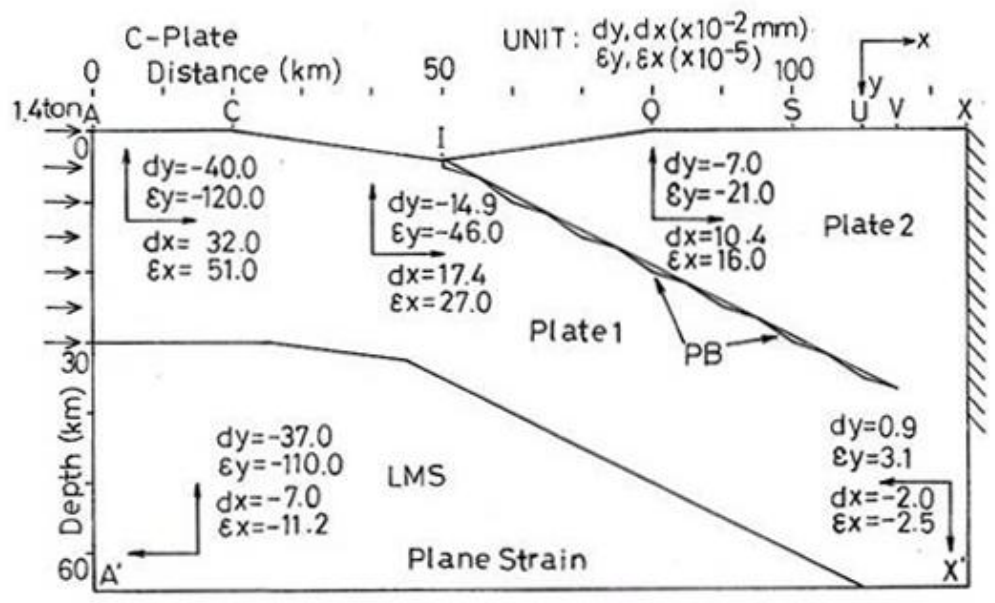

(a)

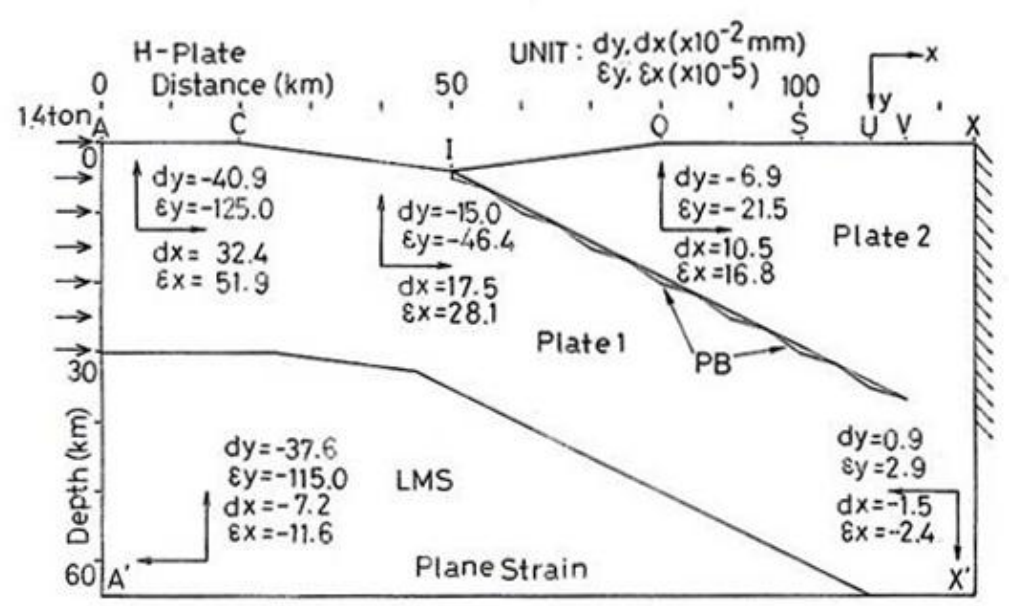

(b)

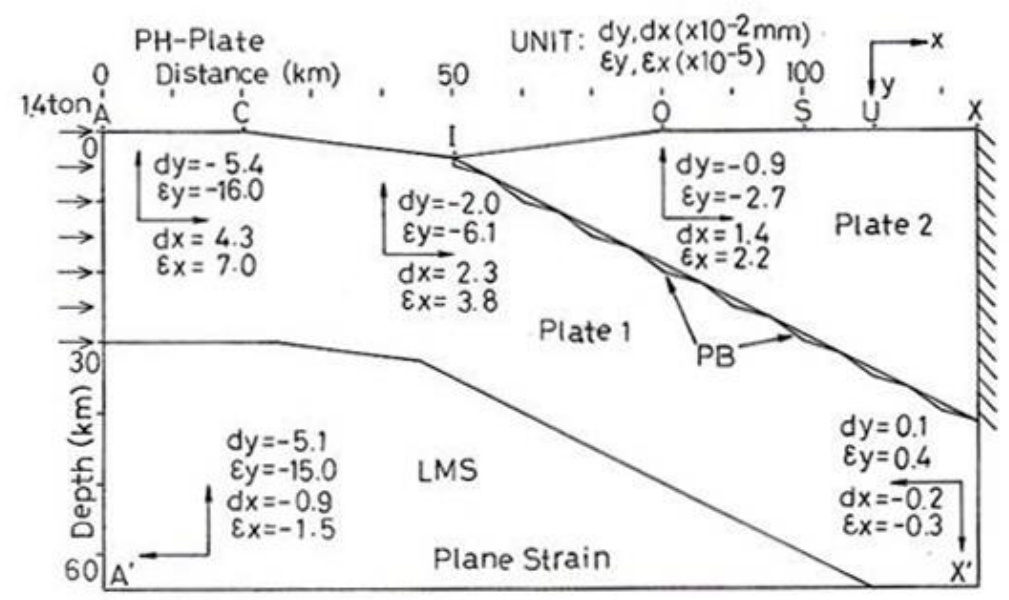

(c)

Fig. 1 Deformation and strain of the plate models without UMB. 


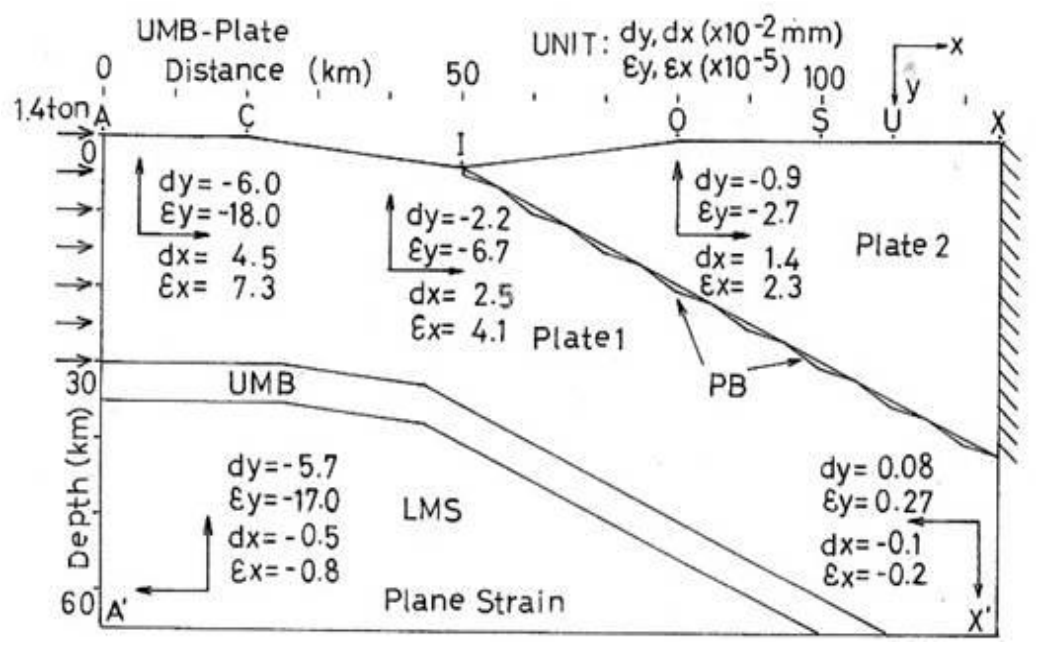

(a)

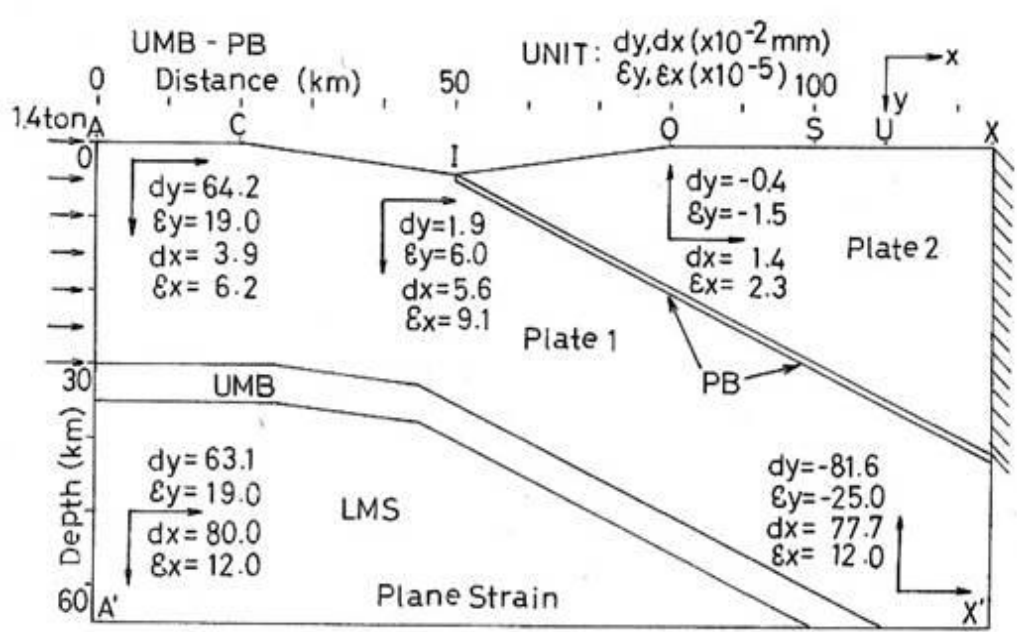

(b)

Fig. 2 Deformation and strain of the plate models with UMB.

rigidity $\mathrm{G}$ and Poisson's ratio $\mathrm{p}$ of the crust and upper mantle in the Philippine Sea plate model [5]. The size of the plate models is $625 \mathrm{~mm}$ and $325 \mathrm{~mm}$ in the horizontal (x-) and vertical (y-) axes, respectively. The thickness of the plate is $2 \mathrm{~mm}$. The lengths enlarged to 200,000 times are shown in the scales of distance $(\mathrm{km})$ and depth $(\mathrm{km})$ in the figure, with the thickness corresponding to $0.4 \mathrm{~km}$. A horizontal compressive force of 1.4 ton applied to the left side of Plate 1 corresponds to the ridge push force of 4.7 MPa. The deformation of the plate models depends on loading conditions, material properties of $\mathrm{PB}$, the existence of $\mathrm{UMB}$, and the shape of PB. The displacement and strain of Plate 1 and Plate 2 for the plate models were calculated by the FEM. The directions of the vertical (dy) and horizontal (dx) displacements are shown by vertical and horizontal arrows, respectively, at sites A, $\mathrm{I}, \mathrm{O}, \mathrm{A}^{\prime}$, and $\mathrm{X}^{\prime}$. The displacement of $0.01 \mathrm{~mm}$ indicated in the figure corresponds to that of $2 \mathrm{~m}$ for the scales of distance $(\mathrm{km})$ and depth $(\mathrm{km})$ designated on the $\mathrm{x}$ - and $\mathrm{y}$-directions, respectively. The vertical

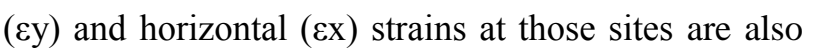
indicated along with the displacement. The vertical displacement at site $\mathrm{O}$ shows uplift for the first type models. However, a few models of the second type show subsidence at site $\mathrm{O}$, in which a tensile force of 0.6-0.7 ton (UMB-X5; UMB-X8) (Fig.3) or 0.35-0.9 ton (UMB-PB-X2; UMB-PB-X) (Fig.4) corresponding 


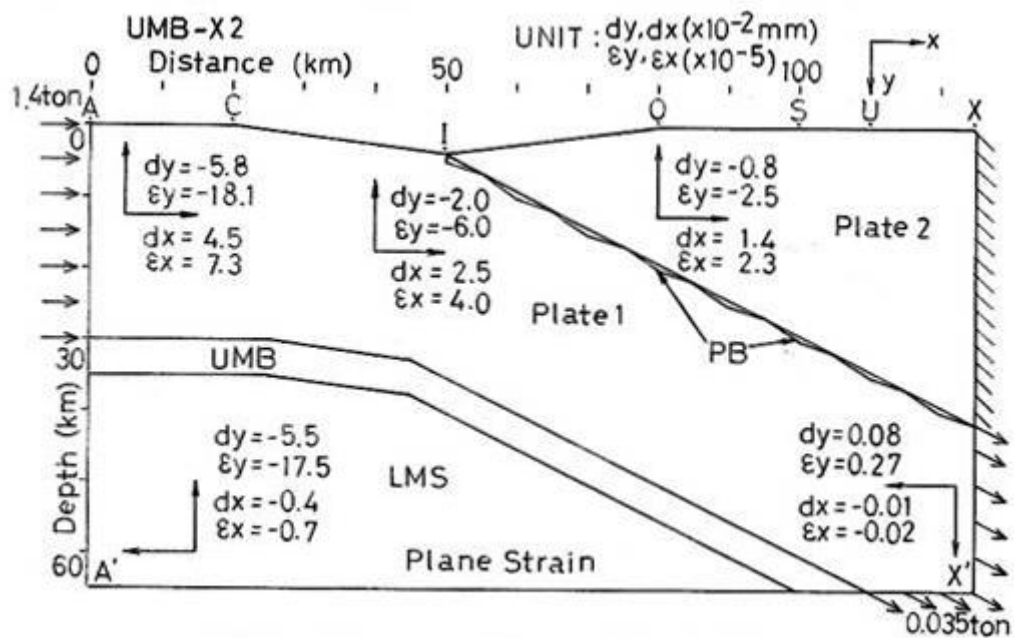

(a)

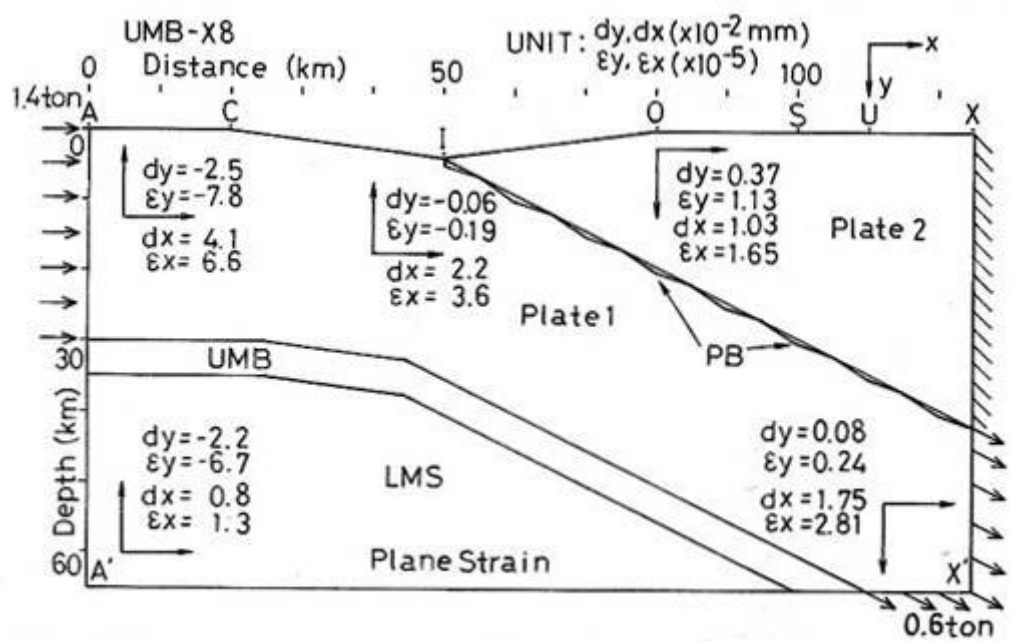

(b)

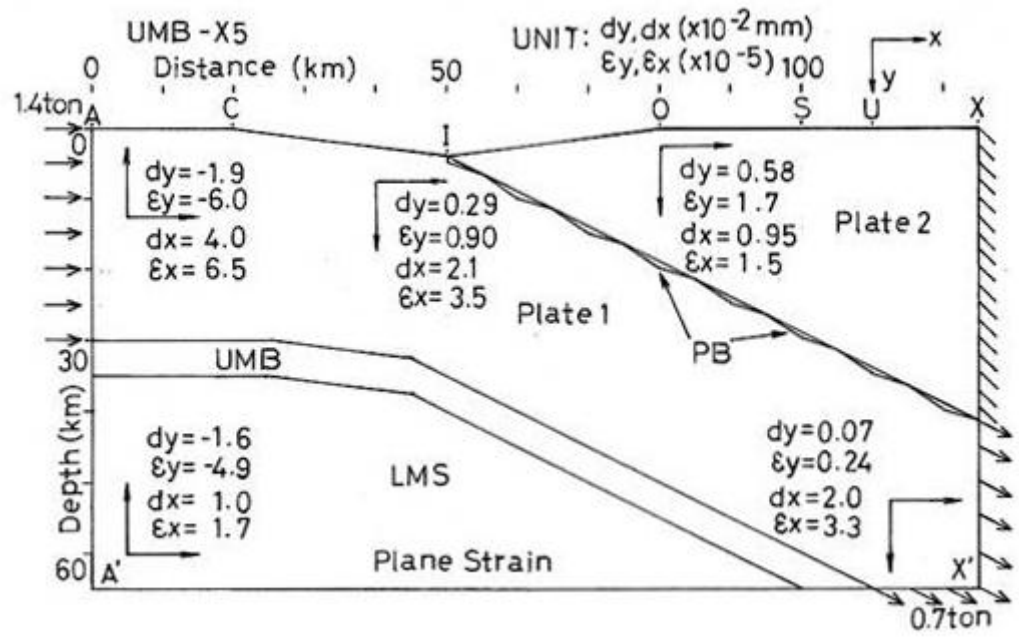

(c)

Fig. 3 Deformation and strain of the plate models with UMB and irregular PB. 


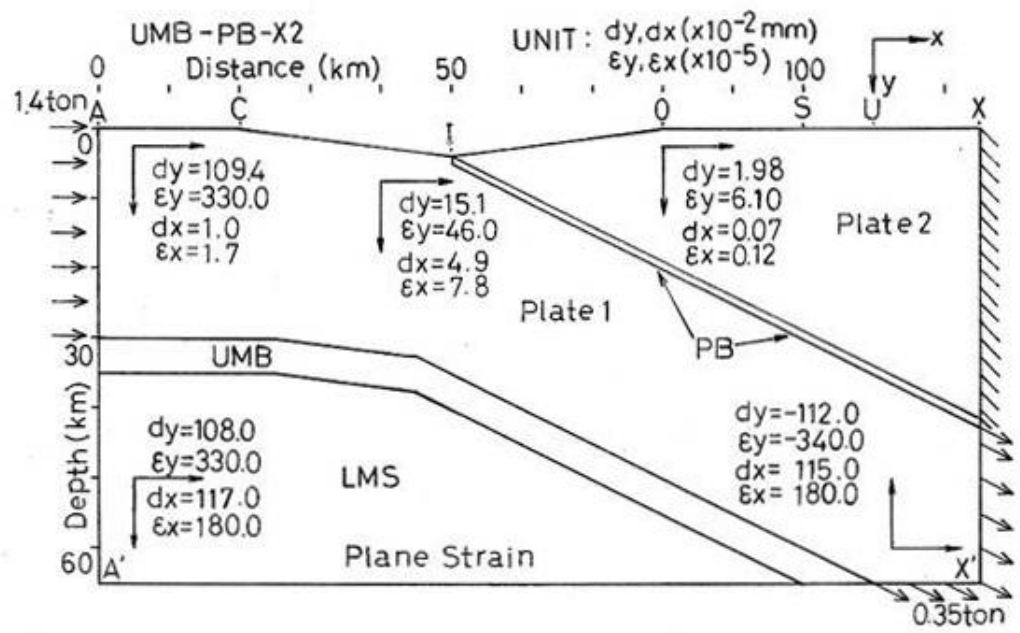

(a)

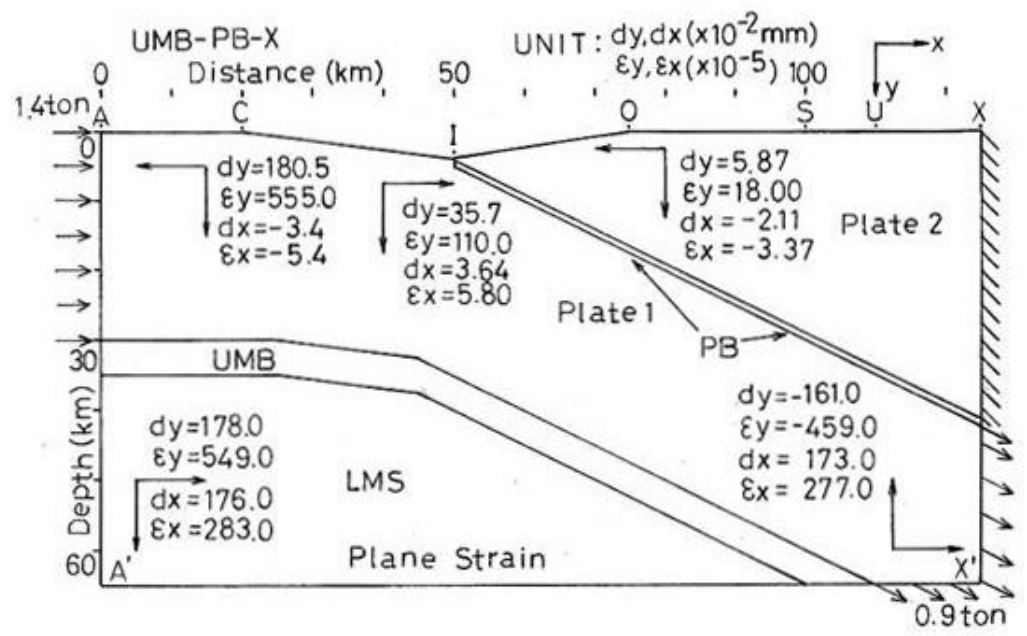

(b)

Fig. 4 Deformation and strain of the plate models with UMB and regular PB.

to the slab pull force is applied to the right side of Plate 1. Furthermore, the horizontal displacements at site $\mathrm{O}$ and site $\mathrm{X}^{\prime}$ for UMB-X5, UMB-X8, and UMB-PB-X2 move toward the right side of Plate 2 . On the contrary, the horizontal displacement at site $\mathrm{O}$ for UMB-PB-X moves toward the left side of Plate 2. With regard to the vertical displacement within the inside of Plate 1, the displacement at site $X^{\prime}$ shows subsidence for UMB-X8 and UMB-X5 (Fig. 3), while it shows uplift for UMB-PB-X2 and UMB-PB-X (Fig. 4). It is noted that the vertical displacement at site I shows uplift for UMB-X8, but it shows subsidence for UMB-X5. These results suggest that the deformation of the vertical and horizontal displacements at sites I,
$\mathrm{O}$, and $\mathrm{X}$ ' for UMB-X5 seems to be qualitatively in harmony with the crustal deformation of the oceanic and continental plates near the subduction zone [7].

\section{Discussion}

The characteristics of the deformation of the plate models exhibit many interesting features: (1) There is no clear difference in the displacement and strain between C-Plate and H-Plate (Fig. 1); that is, the small change of material property of LMS, with the Young's modulus of $\mathrm{H}$-Plate being smaller by $0.3 \%$ than that of Plate 1, does not affect the deformation of Plate 1, Plate 2, and LMS. (2) The displacement and strain for $\mathrm{PH}-\mathrm{Plate}$ are approximately smaller by one figure 
Table 1 Material properties.

(a) C-Plate

\begin{tabular}{llll}
\hline No. & \multicolumn{2}{l}{ Young's modulus $\left[\mathrm{kg} / \mathrm{mm}^{2}\right]$} & Poisson's ratio \\
\hline (1) Plate1 & $2.1 \mathrm{E}+4$ & $(\mathrm{E} 1)$ & $0.3(v 1)$ \\
(2) Plate2 & $2.1 \mathrm{E}+4$ & $(\mathrm{E} 1)$ & $0.3(v 1)$ \\
(3) PB & $1.89 \mathrm{E}+4$ & $(\mathrm{E} 1 \times 0.9)$ & $0.33(v 1 \times 1.1)$ \\
(4) LMS & $2.73 \mathrm{E}+4 \quad(\mathrm{E} 1 \times 1.3)$ & $0.33(v 1 \times 1.1)$ \\
\hline
\end{tabular}

(b) H-Plate

\begin{tabular}{lll}
\hline No. & \multicolumn{1}{l}{ Young's modulus $\left[\mathrm{kg} / \mathrm{mm}^{2}\right]$} & Poisson's ratio \\
\hline (1) Plate1 & $2.1 \mathrm{E}+4 \quad(\mathrm{E} 1)$ & $0.3(v 1)$ \\
(2) Plate2 & $2.1 \mathrm{E}+4 \quad(\mathrm{E} 1)$ & $0.3(v 1)$ \\
(3) PB & $1.89 \mathrm{E}+4 \quad(\mathrm{E} 1 \times 0.9)$ & $0.33(v 1 \times 1.1)$ \\
(4) LMS & $2.0937 \mathrm{E}+4 \quad(\mathrm{E} 1 \times 0.997)$ & $0.3465(v 1 \times 1.155)$ \\
\hline
\end{tabular}

(c) PH-Plate

\begin{tabular}{lll}
\hline No. & Young's modulus [MPa] & Poisson's ratio \\
\hline (1) Plate1 & $1.65 \mathrm{E}+5$ & 0.25 \\
(2) Plate2 & $1.65 \mathrm{E}+5$ & 0.25 \\
(3) PB & 1.65 & 0.46 \\
(4) LMS & $1.708 \mathrm{E}+5$ & 0.298 \\
\hline (d) UMB-Plate and UMB-PB & & \\
\hline No. & Young's modulus [MPa] \\
\hline (1) Plate1 & $1.65 \mathrm{E}+5$ & Poisson's ratio \\
(2) Plate2 & $1.65 \mathrm{E}+5$ & 0.25 \\
(3) PB & 1.65 & 0.25 \\
(4) UMB & 1.65 & 0.46 \\
(5) LMS & $1.708 \mathrm{E}+5$ & 0.46 \\
\hline
\end{tabular}

than those for C-Plate and H-Plate (Fig. 1). This is caused by the reason that the Young's moduli of Plate 1, Plate 2, and LMS for PH-Plate are larger by about one figure than those for C-Plate and H-Plate (Table 1). (3) The deformation characteristics of PH-Plate without UMB are almost close to those of UMB-Plate with UMB (Fig. 1 and Fig. 2). This result means that the existence of UMB does not influence the deformation characteristics of Plate 1, Plate 2, and LMS. (4) The downward displacement at site A and site $I$ and the upward displacement at site $X^{\prime}$ for UMB-PB with regular PB show reverse ones at those sites for UMB-Pate with irregular PB (Fig. 2). This result shows that the shape of $\mathrm{PB}$ strongly influences the characteristics of the displacement inside Plate 1. (5) The deformation characteristics of UMB-X2 with a small downward tension on Plate 1 are close to those of UMB-Plate without a downward tension on Plate 1 (Fig. 3 and Fig. 2). (6) The vertical displacements at site A and site A' located at the left side of Plate 1 and LMS, respectively, for the plate models with UMB and irregular PB such as UMB-X2, UMB-X8, and UMB-X5 show uplift even if the downward tensile force is applied to Plate 1 (Fig. 3). (7) But, the vertical displacements at site A and site A' for UMB-PB-X2 and UMB-PB-X with UMB and regular PB show subsidence (Fig. 4). Thus, the existence of regular PB influences the deformation of the left sides of Plate 1 and LMS, the left sides being located far away from the right side of Plate 1. (8) The movement toward the left side of Plate 2 at site O for UMB-PB-X (Fig. 4) seems to be unreasonable compared to the crustal movement of the continental plate. This result suggests that a large downward tensile force on Plate 
1 for the plate models with UMB and regular PB is not adequate for loading conditions.

It is noted here about PB and UMB. The viscosity of the oceanic plate and the plate boundary is estimated using strain rate and reported [7]. According to the report, the viscosity of the low viscosity layer below the oceanic plate is $10^{18-19} \mathrm{~Pa} \cdot \mathrm{s}$, and the viscosities of the plate boundary and the inside of the continental plate are $10^{21} \mathrm{~Pa} \cdot \mathrm{s}$ and $10^{24} \mathrm{~Pa} \cdot \mathrm{s}$, respectively. The viscosity of the upper mantle is $10^{19}$ $\mathrm{Pa} \cdot \mathrm{s}$ in the earthquake cycle simulation [5]. In the plate models UMB-Plate and UMB-PB the viscosity is neglected because short term forces are concerned. In the present study, instead, a low elasticity layer consisting of a material with rubber-like-elasticity is assumed on the uppermost upper mantle boundary (UMB) and on the boundary (PB) between the oceanic and continental plates, in which Young's modulus of the boundary layers is reduced to $1 / 100,000$ compared to those of the crust and upper mantle. Although the effect of $\mathrm{PB}$ and $\mathrm{UMB}$ on the deformation characteristics of Plate 1, Plate 2, and LMS are discussed in this section, the effect of PB and UMB on the shear stress characteristics should be examined and will be reported independently.

It is reported that the ridge push force is on the order of $10^{12} \mathrm{~N} / \mathrm{m}$ [8] and gives a stress of a few MPa [9]. A horizontal compressive force of 1.4 ton corresponding to $4.7 \mathrm{MPa}$ applied to the left side of Plate 1 is close to the ridge push force described above. When the great earthquaks in Japan occur, the strain is estimated about $10^{-4}-10^{-6}$ [7]. The vertical ground motion of about $1 \mathrm{~m}$ is observed when the great earthquakes in Japan occur near the subduction zone of the Philippine Sea plate [10-12]. The deformation characteristics at site $\mathrm{O}$ on Plate 2 such as dy = $0.37-0.58 \mathrm{~mm}$ corresponding to $2 \times(0.37-0.58) \mathrm{m}$ and ey $=(1.13-1.7) \times 10^{-5}$ as seen in the plate models UMB-X8 and UMB-X5 (Fig. 3) are comparable to those of the crustal vertical displacement and strain for the great earthquakes described above.
In the present plate models, the thickness of the oceanic plate is assumed to be $30 \mathrm{~km}$. The dip angle of Plate 1 is $10 \mathrm{deg}$. at shallow parts between site $\mathrm{C}$ and site I, and $27 \mathrm{deg}$. at deeper parts beneath from site I to site V for C-Plate and H-Plate; and beneath from site $\mathrm{I}$ to site $\mathrm{X}$ for PH-Plate, UMB-Plate, and UMB-PB. The dip angle of the Philippine Sea plate is about $10 \mathrm{deg}$. [5]. So, keeping the dip angle $10 \mathrm{dig}$. of Plate 1 at shallow and deeper parts, the deformation characteristics of Plate 1 (oceanic plate), and Plate 2 (continental plate) pertinent to the Tokai district near the Suruga trough will be determined more properly.

\section{Conclusion}

The deformation characteristics of the elastic plate models composed of the materials of mild steel plate and oceanic crust have been investigated by the use of 2-D FEM in the case of plane strain. In the plate models a horizontal compressive force and a downward tensile force associated with the ridge push and the negative buoyancy of subducting oceanic plate, respectively, are taken into account for loading conditions. The transitional boundary zones placed between Plate 1 (oceanic plate) and Plate 2 (continental plate); and between Plate 1 and LMS (upper mantle) are assumed to be extremely low elasticity layers. The simulation result suggests that if the adequate downward tensile force along with the horizontal compressive force is applied to Plate 1, the deformation of Plate 2 shows the vertical displacement and strain comparable to the crustal deformation near the subduction zone of the Philippine Sea plate when great earthquakes occur in the Tokai district.

\section{References}

[1] Yoshida, M. 2010. "Stress and Strain of Mild Steel Plate with Cracks due to Horizontal Compression." In Proceedings of the 29th Japan Simulation Conference, 391-4.

[2] Yoshida, M. 2011. "Shear Stress Distribution of Mild Steel Plate with Cracks due to Horizontal Compression." In Proceedings of the 30th Japan Simulation Conference, 
$72-5$

[3] Yoshida, M. 2013. "Shear Stress Distriburions of Oceanic and Continental Plates near a Subduction Zone as Inferred from 2-D FEM Elastic Plate Models." International Conference on Simulation Technology, 370.

[4] Hyodo, M., and Hirahara, K. 2004. "GeoFEM Kinetic Earthquake Cycle Simulation in Southwest Japan.” Pure and Applied Geophysics 161: 2069-90.

[5] Hori, T., Hyodo, M., and Hirahara, K. 2004. "Toward Large Scale Numerical Simulations of Earthquake Cycles on Faults in a Three-dimensional Inhomogeneous Viscoelastic Medium." BUTSURI-TANSA 57 (6): 639-49.

[6] National Astronomical Observatory. 2002. Rika Nenpyo (Chronological Scientific Tables.). Maruzen Co. Ltd., 395.

[7] Seno, T. 1995. Fandamentals of Plate Tectonics. Asakura Publishing Co. Ltd., 1-40.

[8] Parsons, B., and Richter, F. 1980. "A Relation between the Driving Force and Geoid Anomaly Associated with Mid-oceanic Ridges.” Earth Planet. Sci. Lett 51: 445-50.

[9] Seno, T. 2008. "Conditions for a Crustal Block to be Sheared off from the Subducted Continental Lithosphere: What is an Essential Factor to Cause Features Associated with Collision." Journal of Geophysical Research 113 (B04414), doi:10.1029/2007JB005038.

[10] Okada, A., and Nagata, T. 1953. "Land Deformation of the Neighborhood of Muroto Point after the Nankaido Great Earthquake in 1946." Bulletin of the Earthquake Research Institute, Tokyo University 31: 169-77.

[11] Ando, M. 1971. "A Fault-origin Model of the Great Kanto Earthquake of 1923 as Deduced from Geodetic Data." Bulletin of the Earthquake Research Institute, Tokyo University 49: 19-32.

[12] Kanamori, H. 1971. "Faulting of the Great Kanto Earthquake of 1923 as Revealed by Seismological Data." Bulletin of the Earthquake Research Institute, Tokyo University 49: 13-18. 